\title{
INFLUÊNCIA DO pH NA SORÇÃO DE ÍONS METÁLICOS EM SÍLICA GEL
}

\author{
H. M. C. FAGNANI ${ }^{1}$, R. C. FERREIRA ${ }^{1}$, M. A. S. D. BARROS ${ }^{1}$, P. A. ARROYO ${ }^{1}$ \\ ${ }^{1}$ Universidade Estadual de Maringá, Departamento de Engenharia Química \\ E-mail para contato: monyke_f@hotmail.com.br
}

\begin{abstract}
RESUMO - A sílica gel é conhecida pela sua capacidade de adsorção e muito utilizada na remoção de metais de soluções aquosas. Quando a sílica gel é submetia à soluções com cargas positivas ou negativas pode ocorrer interações fracas. Esta interação pode ser responsável pela liberação de alguns cátions novamente para as águas residuais, o que pode comprometer a qualidade da água. Assim, este trabalho teve como objetivo investigar a real contribuição dos fenômenos de sorção. Os experimentos de cinética e de equilíbrio foram realizados utilizando sílica gel como adsorvente, a partir de soluções sintéticas de íons de $\mathrm{Ca}^{2+}$ e de $\mathrm{Mg}^{2+}$. A sílica gel foi caracterizada de acordo com o seu ponto de carga zero $\left(\mathrm{pH}_{\mathrm{PCZ}}\right)$. O estudo foi realizado em diferentes condições de $\mathrm{pH}$ : $\mathrm{pH}<\mathrm{pH}_{\mathrm{PCZ}} ; \mathrm{pH}=\mathrm{pH}_{\mathrm{PCZ}}$ e $\mathrm{pH}>\mathrm{pH}_{\mathrm{PCZ}}$. Pode-se concluir que a contribuição da sorção foi maior quando o $\mathrm{pH}>\mathrm{pH}$ PCZ. Justificado pela atração das cargas negativas que foram criadas na superfície do material pelas cargas positivas dos cátions da solução.
\end{abstract}

\section{INTRODUÇÃO}

A remoção de cátions de metais de soluções pode ser realizada por vários processos, tais como precipitação química, extração por solvente, filtração por membrana, osmose reversa, eletrodiálise, adsorção sobre carvão ativado ou troca iônica (Vieira, et al., 2010; Bailey, et al., 1998). Estas técnicas convencionais podem reduzir os níveis de íons metálicos no meio aquoso, mas não é altamente eficaz devido às limitações na variação de pH (Awwad e Farhan, 2012), motivo pelo qual este parâmetro deve ser investigado.

O pH é um parâmetro chave, juntamente com a concentração de metal e composição da solução, na determinação dos níveis de sorção. E, apesar de sua importância, há pouca literatura que reporta o efeitos do pH na adsorção dos íons em estudo: cálcio (Qin, et al., 2010) e magnésio.

Os ensaios de adsorção foram realizados com a sílica gel, a qual possui um considerável interesse quanto aos estudos da suas propriedades de adsorção de moléculas ou íons (Mitchell, 1966). Seu comportamento químico, permite não só a adsorção física de várias substâncias mas, também, reações químicas com moléculas orgânicas. Muita pesquisa é desenvolvida a fim de determinar o processo mais eficiente sem, contudo, investigar a real contribuição de cada parâmetro. Neste sentido, o presente trabalho tem por objetivo avaliar a influência do $\mathrm{pH}$ no processo de sorção, que envolve a troca iônica e a adsorção, na remoção de íons cálcio e magnésio. 


\section{MATERIAIS E MÉTODOS}

\subsection{Sílica Gel}

A amostra de sílica gel da marca Fluka foi caracterizada por adsorção e dessorção de $\mathrm{N}_{2}$, utilizando o equipamento Micromeritics, modelo ASAP 2020, com o objetivo de obter a área específica, o volume de poros e a distribuição de poros. Foi também obtido o ponto de carga zero ( $\mathrm{pH}$ PCZ). Este parâmetro prevê a carga na superfície do adsorvente em função do $\mathrm{pH}$ (Silva, et al., 2010). O procedimento adotado para a realização dessa caracterização é baseado no método descrito por Regalbuto e Robles (2004). Os ensaios de cinética e equilíbrio de adsorção foram realizados em soluções com $\mathrm{pH}$ menor, igual e maior do que o $\mathrm{pH}_{\mathrm{PCZ}}$.

\subsection{Soluções}

As soluções foram preparadas a partir de cloretos de cálcio $\left(\mathrm{CaCl}_{2}\right)$ e de magnésio $\left(\mathrm{MgCl}_{2}\right)$. Estes sais foram escolhidos pois os cátions possuem mesma valência e precipitam em soluções muito básicas, em pH acima de 9 (Shriver e Atkins, 2003). As soluções foram preparadas na concentração de 15 meq. $\mathrm{L}^{-1}$ dos cátions. Por fim o $\mathrm{pH}$ foi corrigido utilizando soluções de ácido clorídrico a 0,1 mol. $\mathrm{L}^{-1}$ e hidróxido de sódio a 0,1 mol. $\mathrm{L}^{-1}$.

\subsection{Ensaios Cinéticos}

As cinéticas de adsorção foram realizadas por meio do contato de 1,2 g de sílica gel com $20 \mathrm{~mL}$ da solução em diferentes valores de $\mathrm{pH}$, na temperatura de $30^{\circ} \mathrm{C}$, sob agitação de $100 \mathrm{rpm}$, com o tempo entre 1 minuto a 12 horas. Após atingido o tempo previamente especificado, o sistema foi filtrado e efetuada a leitura da concentração de metal residual na solução por espectrofotometria de absorção atômica. Os testes foram realizados em triplicata. Por meio do balanço de massa foi possível determinar a quantidade de íons adsorvidos:

$$
q_{t}=\frac{\left(C_{0}-C_{t}\right) \cdot V}{W}
$$

em que $q_{t}$ é a capacidade de equilíbrio dos íons de metal do adsorvente (meq. $\mathrm{g}^{-1}$ ), $C_{0}$ e $C_{t}$ são a concentração inicial e no equilíbrio (meq. $\mathrm{L}^{-1}$ ) de íons de metal na solução, $V$ é o volume da solução (L) e $W$ é a massa de adsorvente ( $\mathrm{g}$ ). Quando se plota q versus tempo se resulta na cinética. Os dados experimentais das curvas cinéticas $\left(q_{t}\right.$ versus $\left.t\right)$, foram ajustados os modelos de pseudo-primeira ordem (Lagergren, 1898), pseudo-segunda ordem (Ho e McKay, 1999) e difusão intrapartícula (Ho et $a l ., 2000)$ de forma não linear, fazendo uso do programa OriginPro 8.5.1.

\subsection{Ensaios de Equilíbrio}

Os ensaios de equilíbrio foram realizados por meio do contato de uma determinada massa de adsorvente com $20 \mathrm{~mL}$ da solução, na temperatura de $30{ }^{\circ} \mathrm{C}$, sob agitação de $100 \mathrm{rpm}$, durante 48 horas. A massa de adsorvente variou de 0,7 à $5 \mathrm{~g}$. Após atingido o tempo previamente especificado, $\mathrm{o}$ 
sistema foi filtrado e efetuada a leitura da concentração de metal residual na solução por espectrofotometria de absorção atômica. Os testes foram realizados em triplicata. Por meio da equação 01 a capacidade de equilíbrio $\left(q_{t}\right)$ foi determinada. Plotou-se $q$ versus $C_{t}$ para obter o gráfico de isoterma de adsorção. E por fỉm, os dados experimentais das curvas de isoterma de adsorção foram ajustados os modelos de Langmuir, Freudlich e Langmuir-Freudlich.

\section{RESULTADOS E DISCUSSÃO}

\subsection{Caracterização da Sílica gel}

A adsorção/dessorção da sílica gel, é apresentada na Figura 1. A Figura 2 apresenta a distribuição de tamanho de poros da sílica gel. Como caracterização do material também foi realizado o pH $\mathrm{PCZ}_{\text {, que é apresentado na Figura } 3 .}$

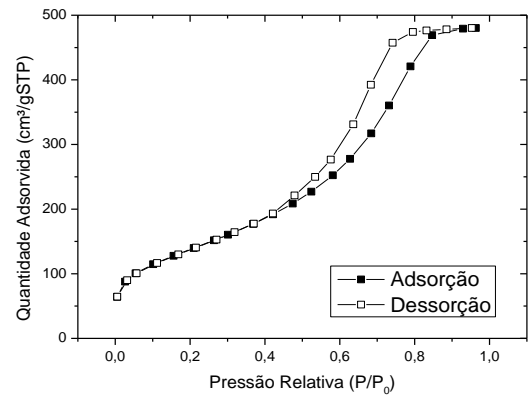

Figura 1 - Isotermas de adsorção/dessorção de $\mathrm{N}_{2}$;

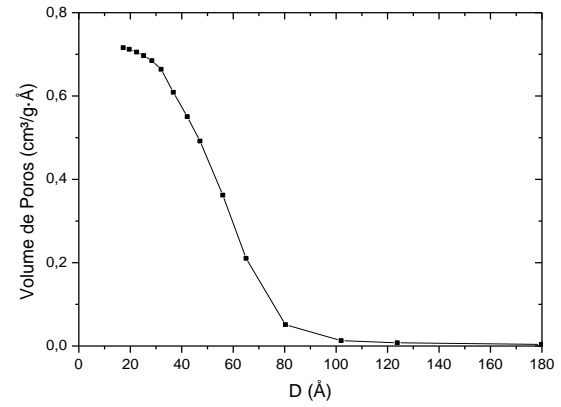

Figura 2 - Distribuição de poros;

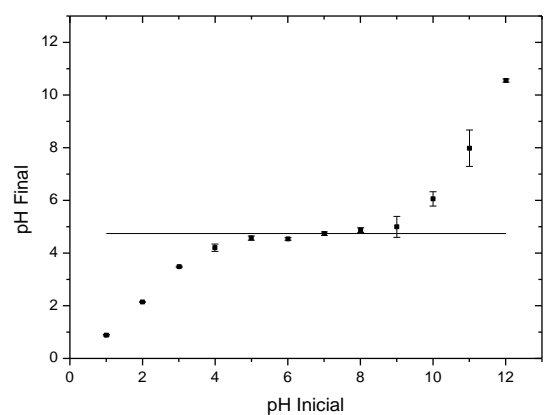

Figura 3 - Ponto de Carga Zero $\left(\mathrm{pH}_{\mathrm{PCZ}}\right)$;

A isoterma de adsorção/dessorção do $\mathrm{N}_{2}$ observado na Figura 1 é tida como isoterma do tipo $\mathrm{V}$ segundo a classificação da IUPAC (1982). Esta curva representa os sólidos macro ou mesoporosos e a quantidade adsorvida tende a um valor finito (Ciola, 1981). A maior concentração dos poros encontrase distribuído entre 20 e $100 \AA$, desta forma, este material é mesoporoso. A tabela 1 apresenta resultados encontrados da caracterização que comprova que a sílica gel é mesoporosa.

Tabela 1 - Caracterização textural dos adsorventes

\begin{tabular}{cc}
\hline Parâmetro & Sílica Gel 60 \\
\hline Área Específica $(\mathrm{BET})\left(\mathrm{m}^{2} \cdot \mathrm{g}^{-1}\right)$ & $503 \pm 1,35$ \\
Diâmetro médio de poros $(\mathrm{BJH})(\AA)$ & 59,1 \\
Volume total de poros $\left(\mathrm{cm}^{3} \cdot \mathrm{g}^{-1}\right)$ & 0,72 \\
Volume de microporos $\left(\mathrm{cm}^{3} \cdot \mathrm{g}^{-1}\right)$ & 0,18 \\
Ponto de carga zero & 4,7 \\
\hline
\end{tabular}

$\mathrm{O} \mathrm{pH}_{\mathrm{PCZ}}$ da sílica gel é de 4,7. Assim, os testes de cinética e de equilíbrio foram realizados nos seguintes valores de $\mathrm{pH}: \mathrm{pH}<\mathrm{pH}_{\mathrm{PCZ}}=2,7 ; \mathrm{pH}=\mathrm{pH}_{\mathrm{PCZ}}=4,7$ e $\mathrm{pH}>\mathrm{pH}_{\mathrm{PCZ}}=6,7$. 


\subsection{Ensaios Cinéticos}

A Figura 4 mostra os pontos experimentais obtidos nos ensaios de cinética de adsorção e os ajustes dos modelos de pseudo-primeira, pseudo-segunda ordens e difusão intrapartícula para o cálcio nos pHs de 2,7, 4,7 e 6,7. A Figura 5, por outro lado, apresenta os ensaios de cinética de adsorção e os ajustes para a sorção do íon magnésio, nos pHs de 2,7, 4,7 e 6,7. Os testes foram realizados até o tempo de equilíbrio, 12 horas. Com a finalidade de melhor visualização do processo de sorção, o pH das solução foram medidos após os testes, apresentado na Figura 6.

a)

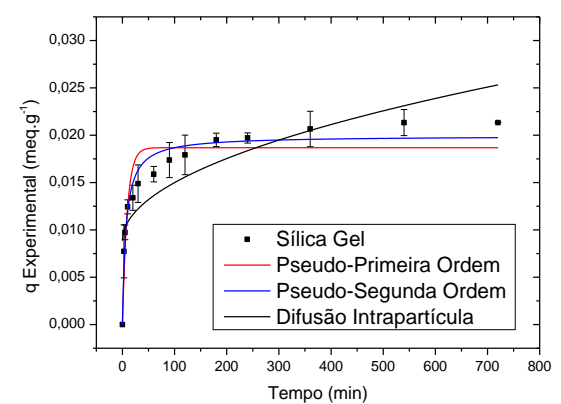

b)

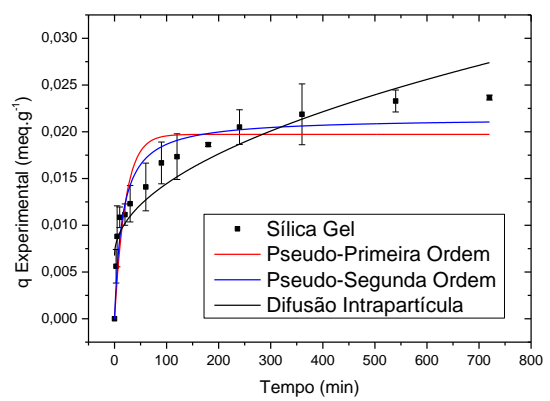

c)

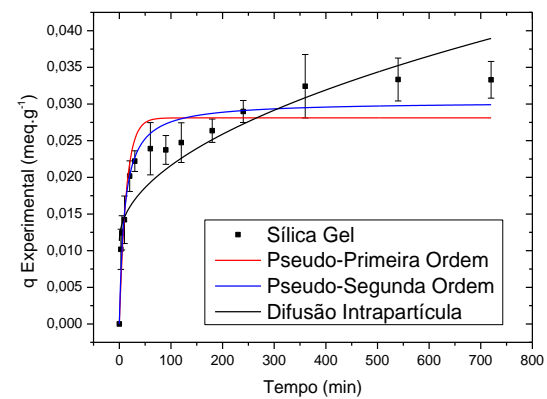

Figura 4 - Resultado da cinética de sorção do $\mathrm{Ca}^{2+} \mathrm{e}$ ajuste dos modelos de pseudo-primeira e pseudo-segunda ordem e difusão intrapartícula, para pH inicial da solução: a) 2,7; b) 4,7; c) 6,7.

a)

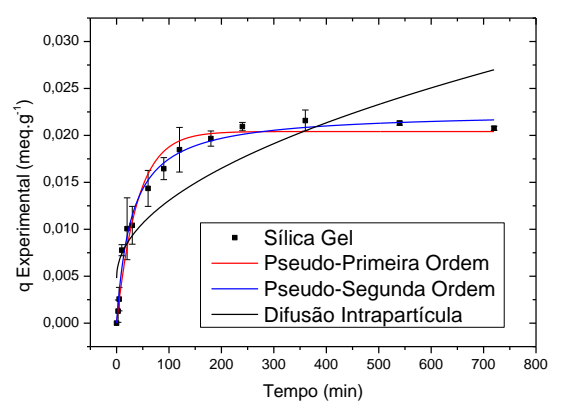

b)

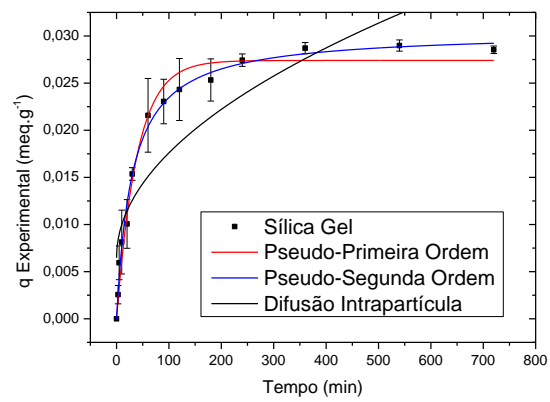

c)

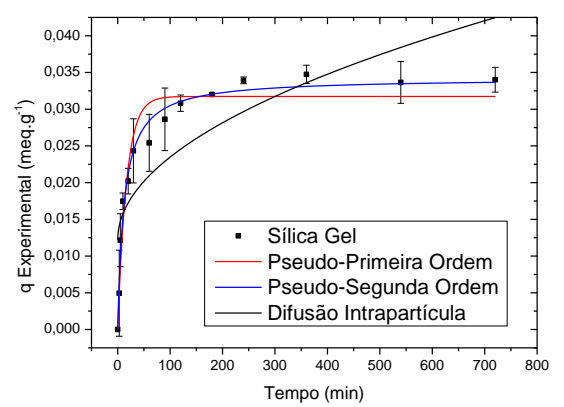

Figura 5 - Resultado da cinética de sorção do $\mathrm{Mg}^{2+}$ e ajuste dos modelos de pseudo-primeira e pseudo-segunda ordem e difusão intrapartícula, para pH inicial da solução: a) 2,7; b) 4,7; c) 6,7.

Verificou-se, por meio das Figuras 4 e 5, para todos os valores de $\mathrm{pH}$ de estudo, o equilíbrio foi alcançado em aproximadamente 240 minutos. Na Figura 4, observou-se, o pH inicial da solução de 6,7 adsorveu 0,033 meq. $\mathrm{g}^{-1}$, seguido do $\mathrm{pH} 4,7=0,022$ meq. $\mathrm{g}^{-1}$ e $\mathrm{pH} 2,7=0,021$ meq. $\mathrm{g}^{-1}$, para íons cálcio. Já para os íons magnésio, Figura 5, o comportamento foi similar. $\mathrm{O}$ pH 6,7 sorveu 0,034 meq. $\mathrm{g}^{-1}$, enquanto o $\mathrm{pH} 4,7=0,029$ meq. $\mathrm{g}^{-1}$ e o pH 2,7 $=0,021 \mathrm{meq} \cdot \mathrm{g}^{-1}$. Assim, para os dois metais, a

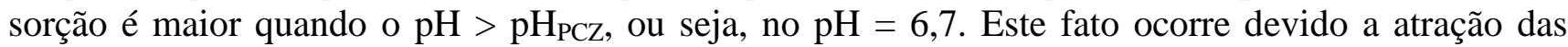
cargas negativas, criada na superfície do material, pelas cargas positivas dos íons metálicos em solução. Desta mesma forma, quando a solução está no $\mathrm{pH}$ abaixo do $\mathrm{pH}_{\mathrm{PCZ}}$, é criado na superfície do material cargas positivas, repelindo o íons metálicos de cargas positivas que estão na solução, justificando assim o fato do $\mathrm{pH}=2,7$ realizar a menor quantidade de sorção. 


\section{9 a 22 de outubro de 2014 \\ Florianópolis/SC}

a)

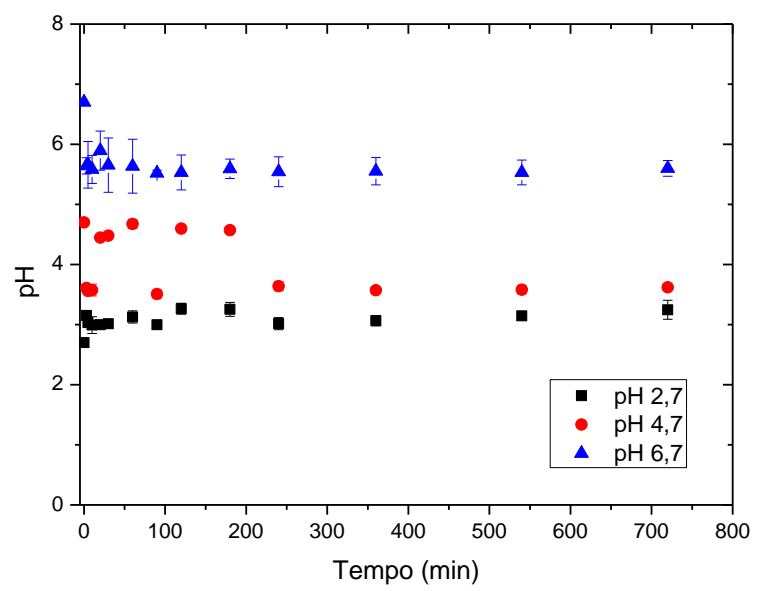

b)

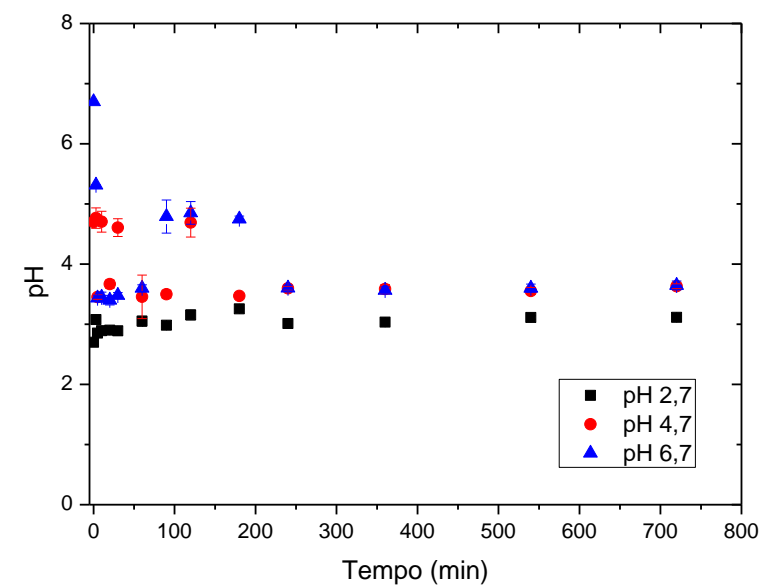

Figura 6-pH da solução após a cinética de sorção para: a) Cálcio; b) Magnésio.

Quando a sorção da sílica gel é realizada em solução que o $\mathrm{pH} \neq \mathrm{pH}_{\mathrm{PCZ}}$ do sólido, criam-se cargas superficiais no sólido. A Figura 6 mostra que há uma tendência dessas cargas superficiais serem neutralizadas e retornarem ao $\mathrm{pH}_{\mathrm{PCZ}}$ no tempo inferior a 50 minutos. Este fato é mais evidente no $\mathrm{pH}$ de 6,7. Assim, conclui-se, que a diferença da quantidade sorvida entre os três valores de $\mathrm{pH}$ inicial da solução, se dá principalmente pela carga criada na superfície do material e não pela capacidade adsortiva da sílica gel. No tempo inferior a 50 minutos o mecanismo de sorção que prevalece é a atração das cargas superficiais com os íons metálicos da solução. E após esse tempo o mecanismo de sorção que prevalece é a adsorção.

A Tabela 2 apresenta os parâmetros da cinética de adsorção obtidos nos ajustes dos modelos de pseudo-primeira e pseudo-segunda ordem para o $\mathrm{Ca}^{2+}$, enquanto que a Tabela 3 apresenta esses

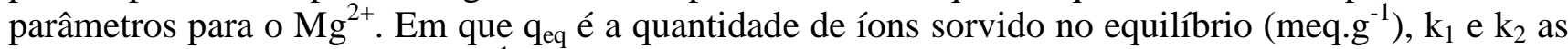
constantes de velocidade $\left(\mathrm{min}^{-1}\right)$ de pseudo-primeira e pseudo-segunda ordem respectivamente. $\mathrm{O}$ modelo de difusão intrapartícula apresentou um comportamento distinto dos dados experimentais, por esse motivo os resultados dos seus parâmetros não serão apresentados neste trabalho.

Tabela 2 - Parâmetros de pseudo-primeira e pseudo-segunda ordem da cinética de sorção do íon $\mathrm{Ca}^{2+}$ em diferentes valores de $\mathrm{pH}$.

\begin{tabular}{|c|c|c|c|c|c|c|c|}
\hline & \multirow{2}{*}{${ }_{(\text {meq. }}^{\left.\text {qu}^{-1}\right)}$} & \multicolumn{3}{|c|}{ eudo-Primeira Ordem } & \multicolumn{3}{|c|}{ Pseudo-Segunda Or } \\
\hline & & eq..$\left.^{-1}\right)$ & & $\mathbf{R}^{2}$ & $\left(\operatorname{meg} g^{-1}\right)$ & & $\mathbf{R}^{2}$ \\
\hline & & & & & & & \\
\hline & & & & & & & \\
\hline & 03 & $0281 \pm 0,0013$ & $0,0754 \pm 0,0177$ & 0,8519 & $0,0303 \pm 0,001$ & $3,2958 \pm 0,794$ & 0,926 \\
\hline
\end{tabular}

Por meio das Tabelas 2 e 3, observou-se que os coeficientes de correlação do modelo de pseudo-segunda ordem foi superior que o de pseudo-primeira ordem, ajustando melhor aos dados experimentais, tanto para o cálcio quanto para o magnésio em todos os $\mathrm{pH}$ iniciais de solução. E os erros do modelo de pseudo-segunda ordem, exceto para o cálcio pH 2,7, são inferiores a 10\%. Sendo 
assim, pode-se dizer, que a cinética de adsorção dos íons metálicos de cálcio e magnésio em sílica gel são representados pelo modelo de pseudo-segunda ordem. Assumindo que a quimissorção é a etapa de controle da velocidade dos processos de adsorção (Ho e Mckay, 1998).

Tabela 3 - Parâmetros de pseudo-primeira e pseudo-segunda ordem da cinética de sorção do íon $\mathrm{Mg}^{2+}$ em diferentes valores de $\mathrm{pH}$.

\begin{tabular}{|c|c|c|c|c|c|c|c|}
\hline & \multirow{2}{*}{$\underset{\left(\mathbf{m e q} \cdot \mathbf{g}^{-1}\right)}{\mathbf{q}_{\text {exp }}}$} & \multicolumn{3}{|c|}{ Pseudo-Primeira Ordem } & \multicolumn{3}{|c|}{ Pseudo-Segunda Orc } \\
\hline & & $q_{\mathrm{eq}}\left(\text { meq. }^{-1}\right)^{-1}$ & & $\mathbf{R}^{2}$ & $(\operatorname{mog}$ & & $\mathbf{R}^{2}$ \\
\hline & & & & & & & \\
\hline & & & & & & & \\
\hline & 0,034 & $0,0317 \pm 0,0010$ & $, 0594 \pm 0,0092$ & 0,9379 & $0,0342 \pm 0,0007$ & $2,3766 \pm 0,3066$ & 0,980 \\
\hline
\end{tabular}

\subsection{Ensaios de Equilíbrio}

A Figura 7 mostra os pontos experimentais obtidos nos ensaios de equilíbrio e os ajustes dos modelos de Lagmuir, Freundlich e Langmuir-Freundlich para os íons cálcio nos valores de pH de 2,7, 4,7 e 6,7. A Figura 8, por outro lado, apresenta os ensaios de equilíbrio e os ajustes para a sorção dos íons magnésio, nos valores de $\mathrm{pH}$ de 2,7, 4,7 e 6,7. Os testes foram realizados até o tempo de equilíbrio, 12 horas.

a)

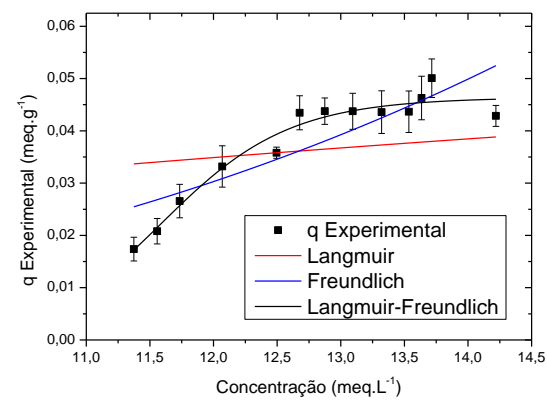

b)

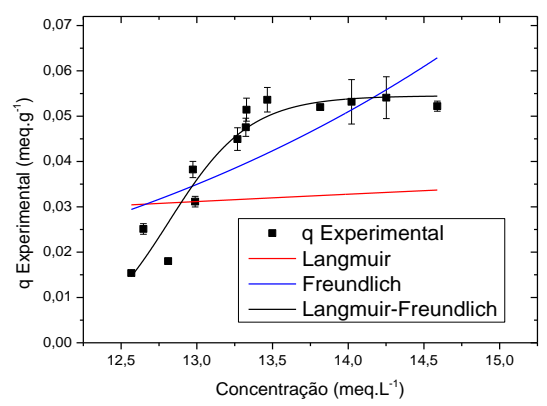

c)

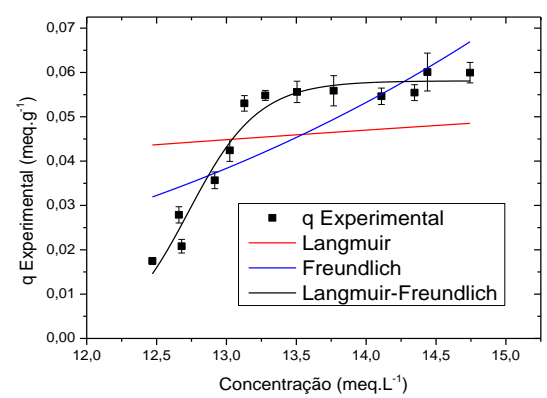

Figura 7 - Resultado da isoterma de equilíbrio de sorção do $\mathrm{Ca}^{2+}$ e ajuste dos modelos de Langmuir, Freundlich e Langmuir-Freundlich para pH inicial da solução: a) 2,7; b) 4,7; c) 6,7.

a)

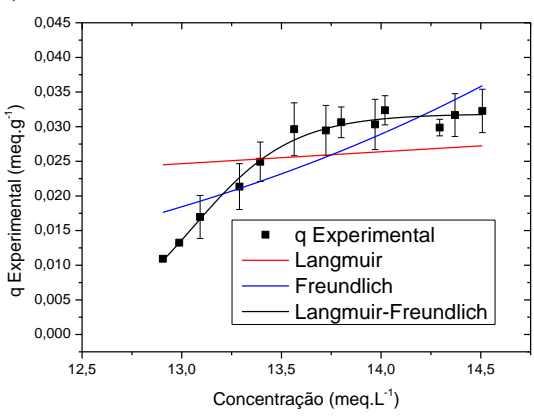

b)

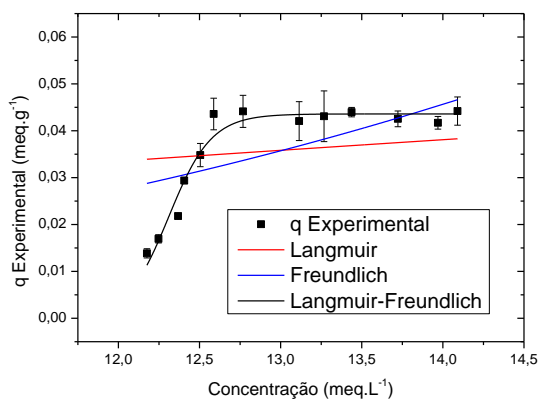

c)

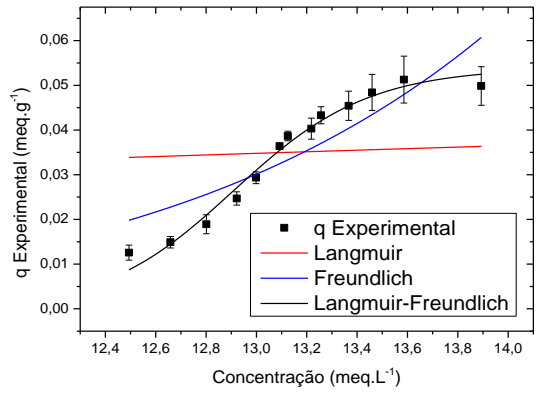

Figura 8 - Resultado da isoterma de equilíbrio de sorção do $\mathrm{Mg}^{2+}$ e ajuste dos modelos de Langmuir, Freundlich e Langmuir-Freundlich para pH inicial da solução: a) 2,7; b) 4,7; c) 6,7. 


\section{9 a 22 de outubro de 2014 \\ Florianópolis/SC}

Na Figura 7, observou-se que a capacidade de adsorção de equilíbrio, dos íons cálcio, no pH 2,7 $=0,044$ meq. $\mathrm{g}^{-1}$, no $\mathrm{pH} 4,7=0,54 \mathrm{meq} \cdot \mathrm{g}^{-1}$ e no $\mathrm{pH} 6,7=0,060 \mathrm{meq} \cdot \mathrm{g}^{-1}$. Enquanto a Figura 8 , a capacidade de adsorção de equilíbrio, dos íons magnésio, no $\mathrm{pH}$ 2,7 = 0,032 meq.g ${ }^{-1}$, no pH 4,7= 0,043 meq.g ${ }^{-1}$ e no pH $6,7=0,050$ meq. $\mathrm{g}^{-1}$. Assim, como na cinética de adsorção, o valor de $\mathrm{pH}$ inicial que apresentou a maior capacidade de adsorção foi o de 6,7 para ambos metais na sílica gel.

É possível verificar nas Figuras 7 e 8 que os modelos de Langmuir e Freundlich não tiveram boa representatividade dos dados experimentais. Assim, a Tabela 4 apresenta os parâmetros obtidos no ajuste do modelo de Lagmuir-Freundlich.

Tabela 4 - Parâmetros de isoterma de adsorção do modelo de Langmuir-Freundlich para os íons

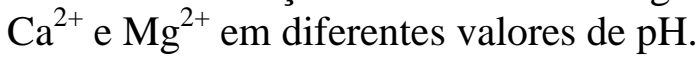

\begin{tabular}{cccccc}
\hline Íons & $\mathbf{p H}$ & $\mathbf{q}_{\text {max. }}\left(\mathbf{m e q . g ^ { - 1 }}\right)$ & $\mathbf{b}$ (L.meq. $\left.{ }^{-\mathbf{1}}\right)$ & $\mathbf{n}$ & \multirow{2}{*}{$\mathbf{R}^{\mathbf{2}}$} \\
\hline \multirow{2}{*}{$\mathrm{Ca}^{2+}$} & 2,7 & $0,0464 \pm 0,0015$ & $0,0860 \pm 0,0005$ & $0,0420 \pm 0,0074$ & 0,9567 \\
& 4,7 & $0,0545 \pm 0,0024$ & $0,0780 \pm 0,0003$ & $0,0203 \pm 0,0040$ & 0,9227 \\
& 6,7 & $0,0581 \pm 0,0016$ & $0,0785 \pm 0,0002$ & $0,0193 \pm 0,0028$ & 0,9578 \\
\multirow{2}{*}{$\mathrm{Mg}^{2+}$} & 2,7 & $0,0319 \pm 0,0005$ & $0,0765 \pm 0,0001$ & $0,0185 \pm 0,0017$ & 0,9857 \\
& 4,7 & $0,0436 \pm 0,0010$ & $0,0812 \pm 0,0001$ & $0,0106 \pm 0,0015$ & 0,9589 \\
& 6,7 & $0,0540 \pm 0,0022$ & $0,0774 \pm 0,0002$ & $0,0204 \pm 0,0022$ & 0,9803 \\
\hline
\end{tabular}

A isoterma de Langmuir-Freundlich quando em baixas concentrações, segue o comportamento da Isoterma de Freundlich, e em altas concentrações, segue a Isoterma de Langmuir. Em que $q_{\max }, b \mathrm{e}$ $n$ são parâmetros. $q_{\max }$ é a capacidade máxima do adsorvente, $b$ representa a razão entre a taxa de adsorção e dessorção e $n$ representa a heterogeneidade do sólido.

A capacidade máxima do adsorvente, para os dois metais, se dá no $\mathrm{pH}$ 6,7. Enquanto a força de sorção, os íons $\mathrm{Ca}^{2+}$ tem a maior força no $\mathrm{pH}=2,7 \mathrm{e} \mathrm{o} \mathrm{Mg}^{2+} \mathrm{em} \mathrm{pH}=4,7$. Isto significa, que o ensaio que teve a maior capacidade de sorção não é o mesmo ensaio que os íons estão mais fortemente ligado ao sólido. Assim, confirma o que foi concluído nos ensaios de cinética de adsorção, que a quantidade sorvida a mais sorvida no valor de $\mathrm{pH}$ 6,7, quando comparado com os outro valores de $\mathrm{pH}$, se dá pela carga criada na superfície do material, sendo esta força mais fraca quando comparado com a adsorção. Quando menor o valor de $n$ mais favorável é a adsorção do metal no sólido. Desta forma, para o cálcio, o $\mathrm{pH}=6,7$ tem a isoterma com a adsorção mais favorável, enquanto o magnésio esse comportamento é observado no $\mathrm{pH}=4,7$.

\section{CONCLUSÕES}

Tanto os ensaios de cinética de adsorção quanto os de isoterma de adsorção dos íons $\mathrm{Ca}^{2+} \mathrm{e}$ $\mathrm{Mg}^{2+}$ em sílica gel mostraram que o valor de $\mathrm{pH}$ no qual se obteve a maior quantidade adsovida foi $\mathrm{pH}=6,7$. Também verificou-se que a força de sorção são maiores em $\mathrm{pH}=2,7$ nos íons $\mathrm{Ca}^{2+} \mathrm{e} \mathrm{pH}=$ 4,7 nos íons $\mathrm{Mg}^{2+}$. Estes fatos ocorrem devido a atração das cargas negativas, criada na superfície do 


\section{9 a 22 de outubro de 2014 \\ Florianópolis/SC}

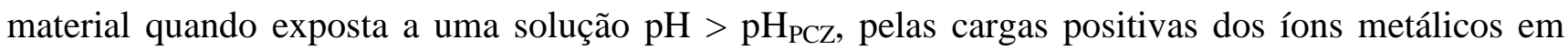
solução, e essa atração é mais fraca do que a adsorção. Também concluiu-se que em tempo inferior a 50 minutos o mecanismo de sorção que prevalece é a atração das cargas superficiais com os íons metálicos da solução. E após esse tempo o mecanismo de sorção que prevalece é a adsorção.

O modelo de pseudo-segunda ordem melhor se ajustou aos dados de cinética de adsorção, assumindo que a quimissorção é a etapa de controle da velocidade dos processos de adsorção. Enquanto o modelo de Langmuir-Freundlich foi o que melhor se ajustou aos dados de isoterma de adsorção, mostrando que a adsorção dos metais na sílica gel é favorável em qualquer valor de $\mathrm{pH}$ estudado.

\section{REFERÊNCIAS}

AWWAD, M. A.; FARHAN, M. A.. Equilibrium, Kinetic and Thermodynamics of Biosorption of Lead (II) Copper (II) and Cadmium (II) Ions from Aqueous Solutions onto Olive Leaves Powder. American Journal of Chemistry, v. 2(4), p. 238-244, 2012.

BAILEY, S. E.; OLIN, T. J.; BRICKA, R. M.; ADRIAN, D. D.. A review of potentially lowcost sorbents for heavy metals. Water Research, v. 33(11), p. 2469-2479, 1998

CIOLA, R.; Fundamentos da Catálise. Ed 1, Editora Moderna, Editora da Universidade de São Paulo, SP, 1981.

HO, Y. S.; McKAY, G. Pseudo-second order model for sorption processes. Process Biochemistry, v. 34, p. 451-465, 1999.

HO, Y.S.; NG, J.C.; McKAY, G.. Kinetics of pollutants sorption by biosorbents: review. Separation Purif. Methods, v. 29, p. 189-232, 2000.

IUPAC: União Internacional de Química Pura e Aplicada. Reporting Physisoption data for gas/solid systems, v. 54, p. 2201-2218, 1982.

LAGERGREN, S. Zur theorie der sogenannten adsorption geloster stoffe. Kungliga svenska vetenskapsakademiens. Handlingar, v. 24, p. 1-39, 1898.

MITCHELL, S. A.. Surface properties of amorphous silicas. Chem. Ind. (London), 1966.

QIN, C.; WANG, R.; MA, W.. Characteristics of calcium adsorption by Ca-Selectivity zeolite in fixed-pH and in a range of pH. Chemical Engineering Journal, v. 156, p. 540-545, 2010.

REGAlBUTO, J. R.; ROBLES, J.. The engineering of Pt/Carbon Catalyst Preparation. University of Illionis: Chicago, 2004.

SHRIVER, D. F., ATKINS, P. W., "Química Inorgânica." $3^{\text {a }}$ edição. Porto Alegre: Bookman, 2003.

SILVA, F. M.; SANTANA, S. A. A.; BEZERRA, C. W. B.; SILVA, H. A. S.. Adsorção do Corante Têxtil Azul de Remazol R por Pseudocaule da Bananeira (Musa sp). Caderno de Pesquisa, v. 17(3), p. 71-77, 2010.

VIEIRA, M. G. A.; ALMEIDA NETO, A. F.; GIMENES, M. L.; da SILVA, M. G.. Sorption kinetics and equilibrium for the removal of nickel ions from aqueous phase on calcined Bofe bentonite clay, Journal of Hazardous Materials, v. 177, p. 362-371, 2010. 